\title{
A METHOD FOR MEASURING THE MOVEMENT OF ROCKS AND GLACIERS WITH SIMPLE EQUIPMENT
}

\author{
E. de Haas*
}

QINCE the beginning of 1953 experiments at the Laboratories of the Hydro$\infty$ Electric Power Commission of Ontario with the method of van Heel (see references) for precision alignment have shown it to be very suitable for measuring small deflections, such as movements of rocks and glaciers.

The basic idea is that three marks are placed on a line with, say, 400 feet between the outer two. They are: a single slit, about $1 / 32$ inch wide, illuminated by a 100-watt projection lamp with condenser lens (Fig. 1); a double slit (Fig. 2), and a $3 x$ eyepiece with a scale (Fig. 3).

The light, originating at the single slit, undergoes diffraction at the double slit, and results in an interference pattern consisting of coloured bands which can be observed with the eyepiece. The set-up resembles the well-known "High School" Fresnel experiments for demonstrating that light is a wave phenomenon.

The applications are based on the fact that the coloured lines are very sharply bounded and that the pattern is symmetrical about its centre. The centres of the first slit, the second slit, and the pattern can always be lined up with great accuracy. Once adjusted the marks can be left in the field for days or months. Any sideways deflection (p) of the double slit $\left(D_{1}\right)$ (Figs. 4 and 5) results in a corresponding sideways deflection (q) in the pattern at the eyepiece scale $(\mathrm{P})$ where

$$
\begin{aligned}
& \mathrm{q}=\frac{\mathrm{c}_{1}+\mathrm{c}_{2}}{\mathrm{c}_{1}} \mathrm{p} \text { or if } \mathrm{c}_{1}=\mathrm{c}_{2} \\
& \mathrm{q}=2 \mathrm{p}
\end{aligned}
$$

$c_{1}$ is the distance between the first slit and the double slit, and $c_{2}$ between the double slit and the eyepiece scale; $q$ is measured on the eyepiece scale as the difference of the average readings of symmetrical coloured lines before and after the deflection occurred.

Using this method we have been able to obtain in the open air on a 400 -foot span an error in $\mathrm{q}$ as small as 2 mils ( 0.002 inch) which corresponds to an error in $\alpha$ of

$$
\Delta \alpha=0.09 \text { seconds of arc }
$$

Working in the enclosure of an 1,100-foot-long inspection tunnel in a concrete power dam we succeeded in spanning a distance of 1,000 feet with an error in $\mathrm{q}$ of 3-4 mils, which corresponds to

$$
\triangle \alpha=0.06 \text { seconds of arc }
$$

\footnotetext{
*Assistant Engineer, Laboratory, Hydro-Electric Power Commission of Ontario.
} 


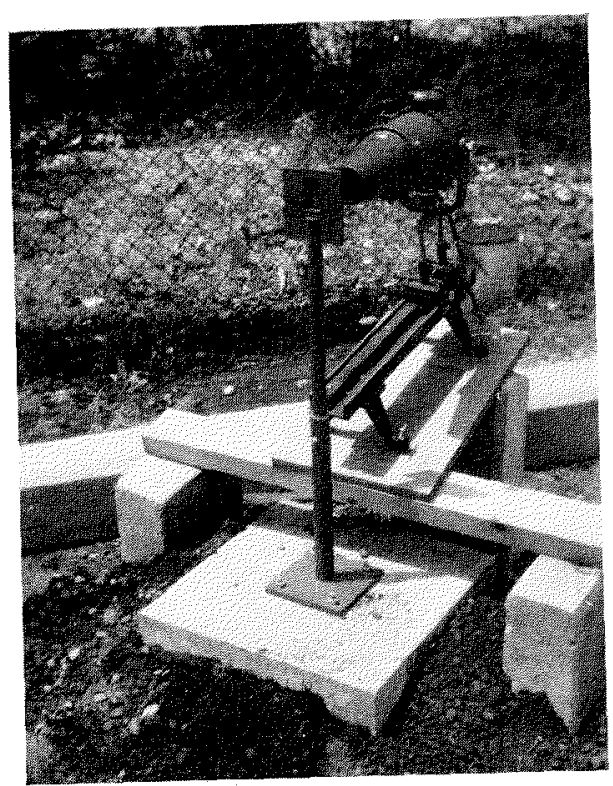

Fig. 1. First slit, illuminated by projection lamp.

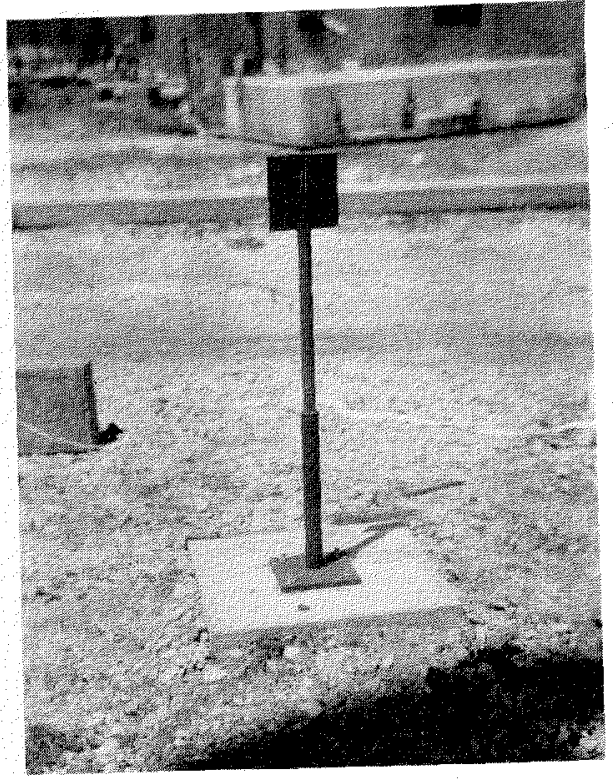

Fig. 2. Double slit, placed between first slit and eyepiece.

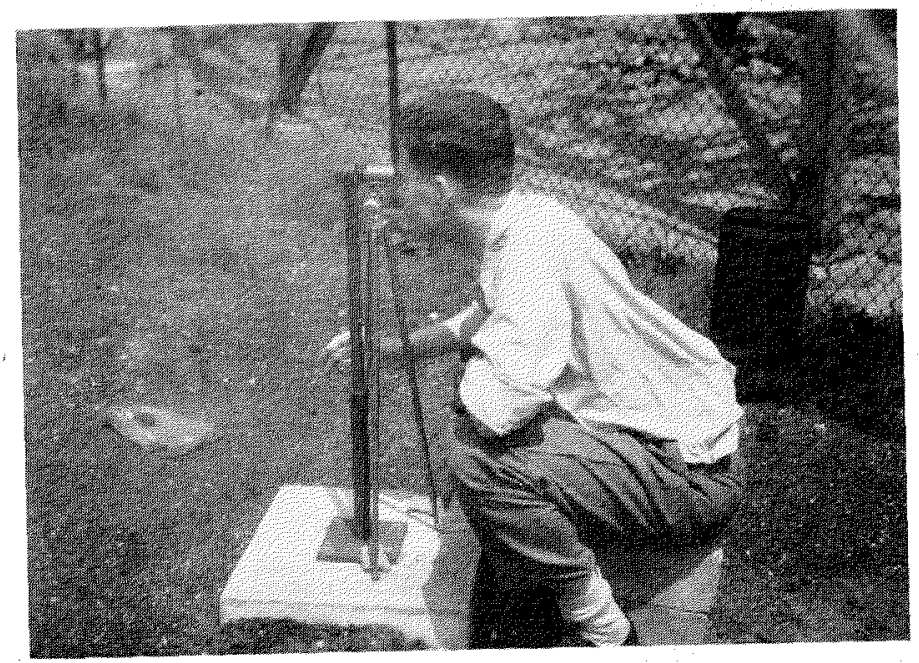

Fig. 3. Eyepiece.

With the present equipment 1,000 feet seems to be the upper limit for convenient operation. A longer distance can be bridged, however, by dividing it up and placing stands at the beginning and end of each section, where each stand is lined up with reference to its two neighbours.

For the study of rock and glacier movements it is suggested that the outer two marks be mounted on solid rocks and the centre mark on the moving rock or glacier.

In our experiments we have made the eyepiece removable and used as the third mark a pointer fixed to the stand. The deflections of the pattern are 


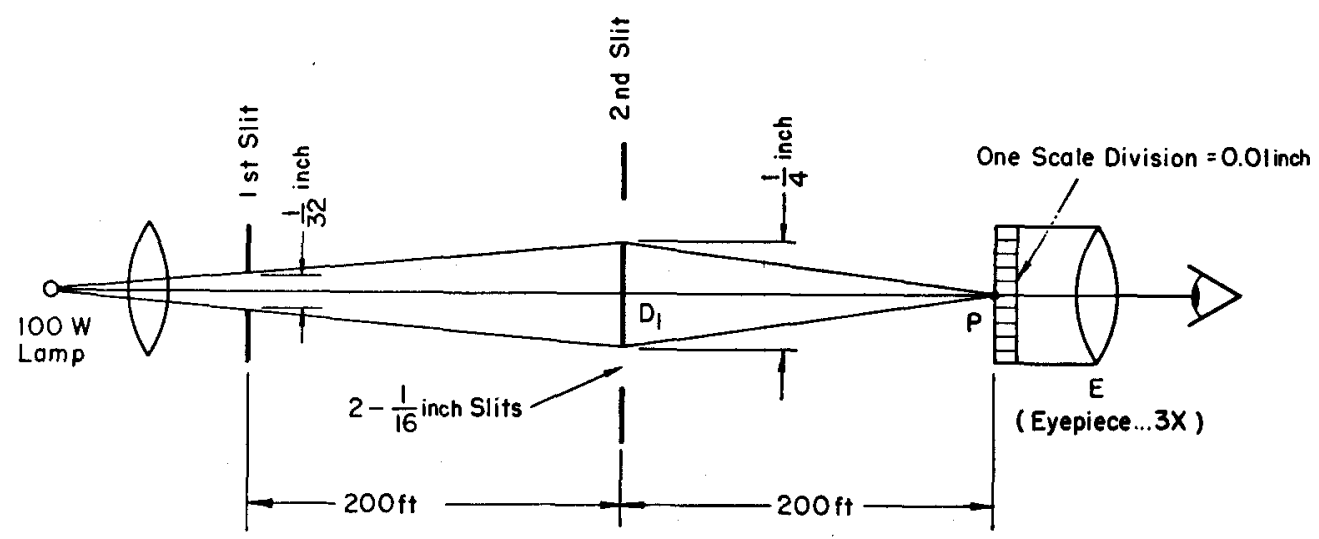

Fig. 4. Alignment method with simple equipment: original position.

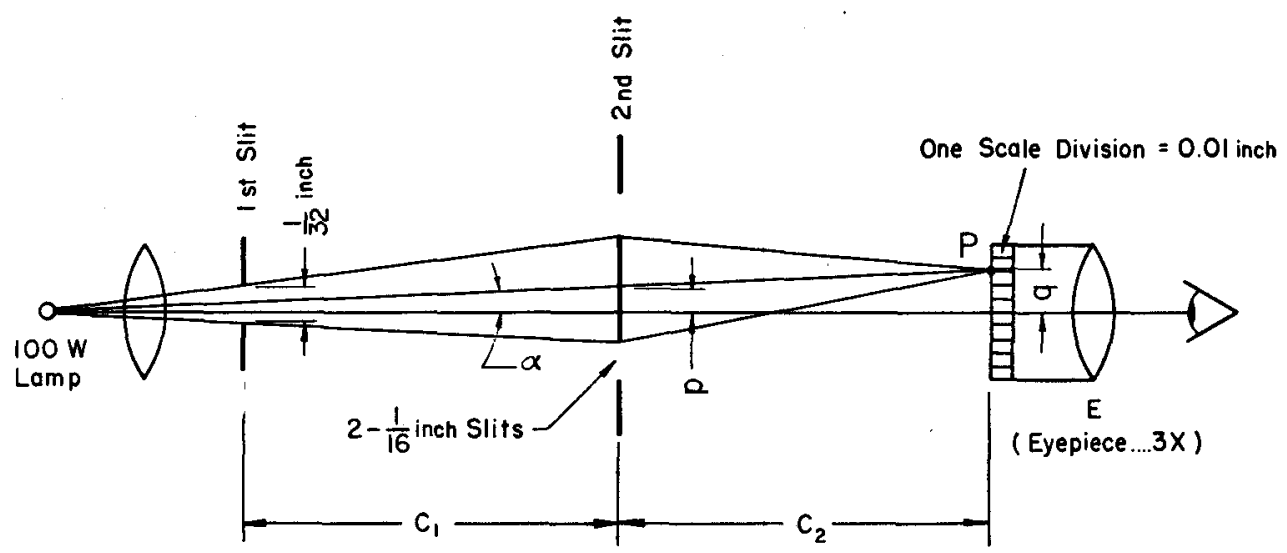

Fig. 5. The second slit has moved over the distance "p".

then noted with reference to this pointer. The lamp, supplied from a storage battery, and the eyepiece are put in place and removed for every series of observations. Thus one lamp and eyepiece can serve several test sites. Only the stands, which can be protected from the weather by plastic bags, have to be left in place permanently.

\section{References}

van Heel, A. C. S. 1949. "Some practical applications of a precision alignment method". Appl. Sci. Res. B1, pp. 306-24.

1950. "High precision measurements with simple equipment". I. Opt. Soc. Amer. Vol. 40, pp. 809-16.

Franx, C. and A. C. S. van Heel. 1951. "Precision alignment in daylight". J. Opt. Soc. Amer. Vol. 41, p. 277. 